\title{
Not stupid, but lazy? Psychological benefits of disruptive classroom behavior from an attributional perspective
}

\author{
Ursula Kessels $^{1}$ (D) Anke Heyder ${ }^{1,2}$
}

Received: 21 January 2020 / Accepted: 5 March 2020 / Published online: 8 April 2020

(c) The Author(s) 2020

\begin{abstract}
Disruptive student behavior is a frequent part of school life, most often shown by male students and related to many negative academic outcomes. In this study, we examined the psychological benefits of engaging in disruptive behavior for lowachieving students from an attributional perspective. In an experimental vignette study of 178 ninth graders from Germany, we tested whether the students' ratings of a target student who displayed disruptive behavior (instead of unobtrusive behavior) in a vignette would evoke lack-of-effort attributions for academic failure through students' expectations of teachers' reprimands. In order to account for the nested data structure (vignettes nested in participants), we applied multilevel analysis while testing for mediation effects. Results showed that the disruptive behavior of a target student triggered lack-of-effort attributions in students instead of lack-of-ability attributions for low academic achievement. This effect was mediated by students' expectations of teachers' reprimands. In addition, low-achieving students showing disruptive behavior were perceived as more popular but less liked personally and as more masculine and less feminine. The study adds to the understanding of disruptive behavior in class as an attempt of poor-performing students to elicit face-saving attributions for academic failure and enhance their peer status.
\end{abstract}

Keywords Academic achievement - Attribution - Disruptive behavior · Effort · Adolescence $\cdot$ Masculinity

Ursula Kessels

ursula.kessels@fu-berlin.de

Anke Heyder

anke.heyder@tu-dortmund.de

1 Department of Education and Psychology, Freie Universität Berlin, Habelschwerdter Allee 45, 14195 Berlin, Germany

2 Present Address: Department of Psychology, Technical University Dortmund, Emil-Figge-Str. 50, 44227 Dortmund, Germany 


\section{Introduction}

Disruptive behavior in class has many negative effects on both students and teachers. Students' misbehavior is related to teachers' burnout (Skaalvik and Skaalvik 2017), stress level, perceived teaching efficacy, and job satisfaction (Collie et al. 2012), and many teachers report being very concerned about how to manage discipline problems in the classroom (Tsouloupas et al. 2010). On the students' side, misbehavior is related to negative academic outcomes reflected by low grades, standardized test scores or graduation rates (Breslau et al. 2011; DiPrete and Jennings 2012; Lynch et al. 2014; Zimmermann et al. 2013). Notwithstanding these negative implications, students still display disruptive behavior, and most of them are male (Trautwein et al. 2004; DiPrete and Jennings 2012).

The currently increasing gender gap regarding grades and school-leaving certificates in favor of female students (Buchmann et al. 2008; Spinath et al. 2014; Voyer and Voyer 2014) seems to be partly due to these differences between male and female students' classroom behavior. Many studies have provided evidence that boys and young men have stronger tendencies toward problem behavior. Male students describe themselves as more disruptive than female students do (e.g., Arbuckle and Little 2004; Demanet and Van Houtte 2012; Finn et al. 2008; Kaplan et al. 2002), and classroom observations (McClowry et al. 2013) and peer nomination studies (e.g., Lynch et al. 2014) have provided corresponding evidence. Also on the level of implicit associations, preservice teachers were found to associate male names more easily with negative behavior and female names with positive behavior than vice versa, and fictitious students with externalizing problem behaviors are usually assumed to be male (Glock and Kleen 2017). Taken together, boys are perceived by both students and teachers as more disruptive than girls are.

In the present experimental study, we examined the psychological benefits of disruptive behavior from an attributional perspective. Attribution theory states that the cause ascribed to failure affects not only students' self-esteem (e.g., Weiner 1994) but also a teacher's reaction to a student's failure (Weiner 1995). If teachers attribute failure to lack of effort, they tend to react with feelings of anger and reprimands (Butler 1994). Our first goal was to test if students expect teachers to respond to disruptive behavior with anger and reprimands and that being reprimanded by the teacher for displaying disruptive behavior indicates that the target student's low achievement is caused by lack of effort rather than lack of ability. Second, we aimed to test whether disruptive behavior also affects students' ascriptions of genderrelated attributes and social outcomes in order to shed more light on the possible psychological mechanisms that contribute to the gender gap in disruptive behavior. We applied an experimental vignette study to determine how students expect teachers to react to disruptive behavior, how they explain the academic failure of a disruptive student, and to identify the attributes they ascribe to the low-achieving disruptive student compared with a low-achieving unobtrusive student.

In the following, we first summarize research on how disruptive behavior is related to negative academic outcomes and to negative teacher reactions such 
as anger and reprimands. We then outline how teachers' reactions to students' academic failure vary with the attributions teachers make for these failures, concluding that when teachers attribute students' low achievement to lack of effort instead of lack of ability, they again show negative reactions such as anger and reprimands. Finally, we summarize existing findings on how students perceive disruptive and low-achieving peers. Combining these different strands of research, the current study tests the hypothesis that academically weak students reap several benefits from being disruptive.

\subsection{Disruptive behavior in school}

Empirical studies have covered a variety of different problem behaviors in the classroom. These behaviors include talking out of turn, disturbing or preventing other students from engaging in classroom activities, yelling out, exhibiting oppositional/noncompliant behavior in response to a teacher's requests (e.g., Arbuckle and Little 2004; Glock 2016; McClowry et al. 2013), externalizing, aggressive behaviors (e.g., Lynch et al. 2014), and even behaviors that result in clinical diagnoses such as conduct disorder or oppositional defiant disorder. Most research has focused on the broader concept of problem behavior or student misbehavior, which includes but is not limited to disrupting the flow of classroom interactions (Morgan and Sideridis 2013).

\subsubsection{Relationship between misbehavior and achievement}

Many studies focusing on the broader concept of problem behavior have shown that students' misbehavior is related to low academic achievement (Morgan and Sideridis 2013). Clear evidence exists for the link between externalizing behavior and low achievement in samples of both elementary and secondary school students, even after confounding variables such as intelligence, gender, ethnicity, family structure, and personality traits have been controlled for (for reviews, see Hinshaw 1992; Zimmermann et al. 2013).

The causal direction of the co-occurrence of problem behavior and academic performance has been a topic of debate (Morgan and Sideridis 2013). One argument suggests that problem behavior causes low achievement by preventing students from paying attention to the teacher and by limiting students' opportunities to learn so they fail to acquire academic skills, thus impeding their academic competence directly (Moilanen et al. 2010). Because externalizing behavior might further lead to social rejection by more academically-oriented peers and result in more associations with deviant peers, such associations might also subsequently lead to less academic engagement and reduced achievement (Morgan and Sideridis 2013). Regarding grades as academic outcomes, the detrimental effect of problem behavior may be magnified because low grades might result from not only lower academic competence but also teachers' sanctioning of misbehavior in class (Zimmermann et al. 2013). However, studies have also demonstrated how experiencing academic difficulties can lead to subsequent problem behavior (Moilanen et al. 2010; Morgan and Sideridis 2013). Learning difficulties may increase students' likelihood of 
engaging in increasingly inappropriate classroom behaviors (Cook et al. 2012). And as failure in school poses a threat to self-esteem, low-achieving students might use problem behavior as an alternative source of self-esteem (Baumeister et al. 2003). In line with these assumptions, adolescents' failure expectations were found to be associated with their active task avoidance, which in turn predicted their norm-breaking behavior and grades (Määttä et al. 2006).

Taking both perspectives together, a bidirectional relationship between externalizing problems and grades seems most plausible. In a longitudinal study of more than 1000 students followed from Grade 5 to Grade 9, the expected reciprocal effects between grades and externalizing problems (which included disruptive behavior but also aggressive and delinquent acts; Zimmermann et al. 2013) were found. Worse grades increased future externalizing problem behavior, which thus resulted in a downward spiral. Self-esteem mediated the effects of school grades on subsequent externalizing behavior (Zimmermann et al. 2013), thus supporting the hypothesis that students use problem behavior to enhance their self-esteem, which is threatened by negative performance feedback. However, teachers identified overachievement more often than underachievement as a possible cause of externalizing behavior and only $17 \%$ of teachers identified attention-seeking as a possible cause of externalizing behavior (Glock and Kleen 2017). These findings highlight that relatively few teachers consider the possibility that problem behavior might result from achievement problems and that students use it in order to enhance their self-esteem (Zimmermann et al. 2013). In the present study, we focused on disruptive classroom behavior in the narrow sense of deliberately disrupting the flow of classroom interactions because this less serious type of misbehavior is part of students' and teachers' daily school experiences (Sullivan et al. 2014).

\subsubsection{Teachers' reactions to disruptive behavior}

Disruptive behavior interrupts the flow of the lesson, disturbs students' learning, and can also challenge teachers' authority when students' behavior is disobedient or oppositional. For all of these reasons, teachers are called upon to respond to students' misbehavior in some way and teachers have reported using a wide range of strategies (Kulinna 2007; Sullivan et al. 2014). The most frequently used strategy that a sample of U.S. American teachers identified when confronted with mild, moderate, or severe disruptive behavior was direct discussion, but in more severe cases also various forms of punishment (e.g., time-out, removing access to a student's favorite activity, and giving lower grades or detention) were named as possible strategies (Kulinna 2007). Using a classroom observation scale, McClowry et al. (2013) found high correlations between observed student disruption and negative teacher feedback $(r=.60)$. A large study with more than 5000 students from three different countries focused on middle school students' perceptions of their teachers' disciplinary strategies (Lewis et al. 2005). Students named a wide range of teachers' discipline strategies, and the students who reported greater levels of misbehavior were more likely to perceive aggression by teachers (e.g., yelling or making sarcastic comments to students who misbehaved; Lewis et al. 2005). In line with the findings that teachers perceive boys as more troublesome and disruptive (Beaman et al. 2007; 
Jones and Myhill 2004; Mullola et al. 2012), male students tend to be reprimanded more than female students (Beaman et al. 2006). To conclude, low-achieving students are more likely to show disruptive behavior than high-achieving students, and teachers very often apply verbal strategies such as discussions and reprimands as reactions to students' disruptive behavior. In the following, we provide initial evidence for our key assumption that the reactions that students expect teachers to show when confronted with disruptive behavior are similar to the reactions teachers show when attributing students' academic failure to a lack of effort.

\subsection{Attributions in school}

Attribution theory deals with the reasons that individuals give to explain their own or others' behavior. The structure of causal thinking comprises three dimensions: the locus, the stability, and the controllability of the causes (Weiner 1995). In brief, attributing low achievement to a lack of effort (instead of a lack of ability) protects students' self-esteem and ascribed aptitude (Weiner 2000). In addition, a large body of research has studied teachers' causal attributions for students' academic success and failure. Next, we summarize findings on teachers' attributions for and reactions to students' academic failure because this study focuses on the benefits of showing disruptive behavior when experiencing academic failure.

\subsubsection{Teachers' reactions to students' academic failure depend on attributions}

As Weiner (2000) describes in his interpersonal theory of motivation, the causes that teachers ascribe to students' success or failure tend to elicit specific reactions in teachers. Regarding academic failure, the dimension of controllability plays a major role in teachers' reactions. When others ascribe a student's failure to a lack of effort, which is subject to volitional control and hence regarded as a controllable cause, the student is perceived as responsible for the outcome. Responsibility for a negative outcome gives rise to anger in teachers, which "in turn, gives rises [sic] to anti-social responses such as punishment and reprimand" (Weiner 2000, p. 7). This means that after teachers make a lack-of-effort attribution, their reactions theoretically resemble their reactions to disruptive behavior as described above. However, when failure is seen as caused by a lack of ability, the attribution is made to an uncontrollable cause, and the student is not held personally responsible. "Lack of responsibility for a negative achievement outcome tends to elicit sympathy" (Weiner 2000 , p. 9), not resulting in punishment or reprimands but in prosocial responses such as help-giving by the teacher.

Empirical evidence supporting this theory stems from studies as early as Weiner and Kukla's (1970). In their vignette experiment, participants were asked to evaluate students who varied in effort (high/low), ability (high/low), and outcome (ranging from excellent to clear failure). As predicted, students low in ability but high in effort received the most praise when they succeeded and the least punishment when they failed, whereas students with high ability who did not put forth effort and failed were especially punished. These first findings were confirmed by many later studies: 
Israeli primary school teachers reported that they would react to student failure that the teachers attributed to lack of ability with pity and offers to help but that they would feel anger in response to students' lack of effort (Butler 1994). Greek Cypriot elementary school teachers reported feeling more anger when failure was caused by a lack of effort and more pity when failure was caused by a lack of ability (Georgiou et al. 2002). When Italian and French teachers attributed students' failure to a lack of effort, the teachers saw the students as responsible for the students' own failure, the teachers felt more anger and less sympathy, and the teachers reacted with more reprimands compared with teachers in the lack-of-ability attribution condition (Matteucci 2007; Matteucci and Gosling 2004). Another study revealed that a stable controllable cause of failure ("the lazy student") elicited the most retribution (e.g., Reyna and Weiner 2001).

\subsubsection{Students' perceptions of teachers' attributions}

Several studies have provided evidence that on the basis of teachers' reactions to failure, students can infer whether teachers attribute the failure to lack of effort or lack of ability, at least from a certain age on (Meyer 1992; Weiner et al. 1982). More specifically, sixth graders inferred correctly from a teacher's reaction (reprimanding or not) whether the teacher attributed a student's failure to lack of effort or lack of aptitude, whereas third graders' interpretations of teachers' reactions were not consistent with attribution theory (Butler 1994). Other experimental studies have confirmed that after failure, sixth graders infer from the affective cues (angry or sorry) shown by others the reasons why the other person thought they failed, inferring an assumption of lack of effort when the person was angry (Graham 1984). A vignette study using eight hypothetical descriptions of classmates in a sample of fifth and 10th graders and college students showed that students believed that teachers and they themselves would show more appreciation of effort exertion than ability. However, they also assumed that a student who was more able and exerted less effort would be more satisfied, and they stated that they themselves would prefer to be perceived as having high ability than as exerting effort (Raviv et al. 1983).

Taken together, prior research has suggested that teachers show similar reactions (e.g., anger or reprimands) to students who show disruptive behavior as they do to students who show low achievement if they attribute students' low achievement to a lack of effort. Students in turn understand that such reactions by teachers indicate that the teacher has attributed a lack of effort to the student but not a lack of aptitude.

\subsection{Students' perceptions of low effort and disruptive peers}

Very different from teachers, students also see potential positive outcomes from misbehavior such as increased fun and social status (Cothran et al. 2009). After school belonging and teachers' support were controlled for, greater peer attachment was even found to be positively related to school misconduct (Demanet and Van Houtte 2012). In the following, we review the findings that led to our hypothesis that lowachieving students exhibiting disruptive behavior will benefit from positive peer 
perceptions compared with unobtrusive low achievers. In line with the idea that teachers will have similar reactions to disruptive students and low effort, we propose that also students' perceptions of disruptive peers should be similar to their perceptions of peers showing low effort. Accordingly, these perceptions should not be limited to lack-of-effort attributions for failure but should extend to ascriptions regarding social and gender-related outcomes.

\subsubsection{Social outcomes}

Adolescents vary in the reasons they give for failure in order to manage their public images in ways that promote social approval from the different actors in the classroom (Juvonen 2000). Particularly in front of their peers, students from adolescence on tend to downplay the amount of work they do for school (Juvonen 2000; Kessels et al. 2008). Students showing low academic effort are motivated by being perceived by their peers as more able than hard-working students (Urdan and Midgley 2001). Correspondingly, effort withdrawal is a frequent behavioral self-handicapping strategy that can provide a face-saving excuse for a student with poor academic achievement (e.g., McCrea and Hirt 2001; Rhodewalt and Fairfield 1991). We propose that disruptive low-achievers are also perceived as more intelligent than unobtrusive low-achievers.

In order to understand how displaying low effort and disruptive behavior are linked to peer status, it is crucial to differentiate between two dimensions of students' peer status (Heyder and Kessels 2017): popularity and likeability. Popularity in adolescence indicates that a student is perceived as powerful and prestigious among his or her classmates. Popularity is assessed by asking students who among their classmates is popular or has many friends. Likeability means to be well-liked by peers and is measured by asking students whom they personally like or want to be friends with (Cillessen and Marks 2011). These two constructs tend to only be moderately related during adolescence (Cillessen and Mayeux 2004; van der Linden et al. 2010) and are differentially related to displaying effort in school. Experimental vignette studies with student samples have revealed different relationships that also depend on age groups and achievement level. Only elementary school children rated lazy students as less popular than hard-working students among their peers. Adolescents, on the contrary, tend to view diligence as facilitating teacher approval but low effort expenditure as improving peer popularity, especially when the target is described as high in ability (Heyder and Kessels 2017; Juvonen and Murdock 1995). Diligent and hard-working students may be perceived as unpopular, but they are not necessarily personally disliked (e.g., Engels et al. 2017; for summaries, see De Bruyn and Cillessen 2006; Heyder and Kessels 2017). Students between the ages of 9 and 13 liked peers less when these peers were perceived as not putting in as much effort as average students in order to do well in school (Lease et al. 2002). In Grade 7, likeability was positively related to both behavioral and emotional academic engagement, while popularity was related to less behavioral engagement (Engels et al. 2017). Also in an experimental vignette study, ninth graders perceived peers displaying low effort as more popular but not as well-liked as hard-working peers (Heyder and Kessels 2017). Thus, similar to displaying a lack of 
effort, showing disruptive behavior might be positively associated with popularity but might also take a toll on students' likeability.

\subsubsection{Gender-related outcomes}

Not only peer status but also perceived masculinity and femininity should be linked to both amount of academic effort (e.g., Heyder and Kessels 2017) and amount of disruptive behavior. Research focusing on possible reasons for gender differences in classroom behavior has included concepts such as gender identity, gender stereotypes, and gender-typical (academic) cultures. In sociological theories (e.g., Francis 2000; Jackson 2002; Jackson and Dempster 2009), being disruptive and rejecting school values and school work (in short, being "laddish") is understood as a means for boys to enhance their masculinity and popularity among peers. Boys are seen as constructing their masculinity in opposition to the more sensible and studious manifestations of femininity (Beaman et al. 2006). In a British interview study, male college students characterized academic effort, hard work, and diligence as key characteristics of the "feminine" way of studying and indicated that these characteristics should thus be avoided by real men, whereas showing low effort and being laddish were reported to stand for masculinity (Jackson and Dempster 2009). From a psychological perspective, a similar argument can be made by stressing that the perceived fit between a student's gender identity and the gender stereotyping of a possible behavior in school (e.g., displaying disruptive behavior or effort) will predict the extent to which at student will engage in that behavior (Kessels et al. 2014). Inventories for assessing femininity and masculinity in adolescent samples (e.g., Krahé et al. 2007) include "diligent" as indicative of femininity, whereas being "lazy," "untidy," and "aggressive" are used to measure (negative) masculinity. An implicit cognition test also revealed that German ninth graders associated school, and academic engagement in general, more strongly with the category "female" than the category "male" (Heyder and Kessels 2013). Furthermore, teachers ascribed less academic engagement to male students if they displayed behaviors that were strongly stereotyped as being very masculine (Heyder and Kessels 2015). In line with this argument, a student displaying disruptive behavior in class would not only be more likely to be male than female but would be perceived as very masculine and as not very feminine.

Taken together, we infer from previous research that low-achieving students will benefit from showing disruptive behavior in class because this might lead to the ascription of lack of effort but not lack of ability and to ascriptions of higher intelligence and popularity. In addition, disruptive behavior might be especially appealing to boys and young men because of an accompanying ascription of masculinity and less femininity.

\subsection{Study overview and hypotheses}

In this study, we examined the psychological benefits of showing disruptive behavior for low-achieving students from an attributional perspective. In a nutshell, we expected that, from the perspective of adolescents, displaying disruptive behavior in class would be perceived as an effective strategy for poor-performing students 
to elicit self-serving attributions for academic failure. To test this, we conducted an experimental vignette study by asking a sample of German adolescents to evaluate descriptions of fictitious target students who were showing disruptive versus unobtrusive behavior. Participants had to evaluate these vignettes in regards to how teachers would likely react to the target students, what the reasons for target students' low achievement might be and what characteristics the target students might have. This study design enabled us to test for causal effects of disruptive behavior exhibited by male and female target students while minimizing other potentially confounding effects such as actual relationships between the students or between students and specific teachers. More precisely, we proposed the following hypotheses regarding (a) students' perceptions of teachers' reactions and students' attributions to lowachieving target students showing disruptive compared with unobtrusive behavior, (b) the effects on social outcomes such as students' popularity, and (c) the effects on gender-related outcomes.

On the basis of prior research on teachers' self-reported reactions to student misbehavior (Kulinna 2007; Sullivan et al. 2014), we expected that a target student's disruptive behavior in a vignette would elicit participants' perceptions that teachers would react with reprimands and anger (H1). Because such reactions resemble those of teachers who attribute students' low achievement to a lack of effort (e.g., Butler 1994; Georgiou et al. 2002), we further expected that a target student's disruptive behavior would elicit lack-of-effort attributions from participants (H2a). In addition, on the basis of earlier research that showed that students infer from teachers' reprimands or anger that the teacher attributes a student's failure to lack of effort (Butler 1994; Graham 1984), we hypothesized that the effect of a target student's disruptive behavior on participants' lack-of-effort attributions would be mediated by participants' expectations of teachers' reprimands and anger (H2b). For lack-ofability attributions, we expected the opposite effect because when teachers attribute a student's failure to lack of ability, they do not reprimand the student (Butler 1994; Georgiou et al. 2002; Weiner 2000). That is, we hypothesized that a target student's disruptive behavior would elicit lower lack-of-ability attributions from participants for the target student's low achievement $(\mathrm{H} 3 \mathrm{a})$. We also expected this effect to be mediated by participants' expectations of teachers' reprimands and anger $(\mathrm{H} 3 \mathrm{~b})$.

As has been shown for students who exhibit low effort, we further expected low-achieving students to benefit from showing disruptive behavior with respect to ascribed popularity and intelligence. Showing low academic effort has been found to be associated with higher popularity (Engels et al. 2017; Heyder and Kessels 2017; Juvonen and Murdock 1995) but lower likeability (De Bruyn and Cillessen 2006; Lease et al. 2002), and students were found to downplay their effort in order to be perceived as more able (Urdan and Midgley 2001). We hypothesized that a target student's disruptive behavior would increase participants' ascriptions of the target student's number of friends and popularity (H4a), decrease participants' liking of and wanting to be friends with the target student (H4b), and increase participants' ascriptions of the target student's intelligence $(\mathrm{H} 4 \mathrm{c})$.

Aiming to shed more light on potential mechanisms behind the gender gap in disruptive behavior (e.g., Arbuckle and Little 2004), we also studied effects on genderrelated outcome variables. Because male students have been found to show more 
disruptive behavior than female students (e.g., McClowry et al. 2013), we expected a disruptive male target student to be perceived as more common (H5a) and more gender-typical (H5b) than a disruptive female target student. Moreover, because disruptive behavior seems to be associated not only with being male (rather than female) but also with being masculine (rather than feminine; e.g., Jackson 2002; Krahé et al. 2007), we hypothesized that showing disruptive behavior would also result in participants ascribing a higher level of masculinity $(\mathrm{H} 5 \mathrm{c})$ and a lower level of femininity to the target student (H5d).

\section{Method}

\subsection{Sample}

The sample consisted of 178 ninth graders (98 female and 79 male students, one who did not indicate gender) from two German academic-track schools (Gymnasium). The students' mean age was $14.67(S D=0.58)$. A total of 164 students reported being born in Germany (13 born in another country, one missing this information), and 109 students reported speaking only German at home (54 both German and another language with equal frequency, 13 mostly a foreign language, two missing this information). The students participated voluntarily during regular school hours and received a chocolate bar for their participation. Informed consent was obtained and the Senate Administration for Education, Youth, and Science in charge of approving empirical research in schools in the authors' city had reviewed and approved the research protocol and questionnaires. Further approval of the protocol by the university ethics committee was not required for projects of this type as research on school students is under direct supervision of the Senate Administration for Education, Youth, and Science.

\subsection{Experimental design and dependent variables}

In order to keep the internal validity of the vignette experiment as high as possible as well as to minimize the risk of biasing the results by providing irrelevant details, we contrasted a student who showed disruptive behavior with a student who did not show disruptive behavior. In detail, participants received a paper-pencil questionnaire in which two fictitious target students with poor grades were described: one who disrupted the class, the other who behaved unobtrusively (within-subjects factor). The target who exhibited disruptive behavior was characterized as follows: "[Name] is 15 years old. His/Her grades are not very good and he/she often barely passes. He/She is an active boy/girl who frequently displays disruptive behavior in class. He/She likes to show his/her classmates funny videos on his/her mobile phone during lessons and often gives impertinent answers to teachers. Sometimes he/she even turns a deaf ear when teachers are talking to him/her. Recently, he/she loudly commented on the teacher's appearance in class." The types of behavior used for the latter vignette were pretested in a pilot study involving 42 teacher training 
students with respect to the extent to which they reflected disruptive behavior (mean rating $M \geq 3.11$ on a scale from $1=$ does not disrupt lessons at all to $4=$ disrupts lessons very much). The target who behaved unobtrusively was characterized as follows: "[Name] is 15 years old. His/Her grades are not very good, and he/she often barely passes. He/She is a quiet boy/girl who behaves rather unremarkably. He/She is very quiet in class and never shows disruptive behavior." This is a very neutral description of a student who does not show disruptive behavior without including any further behaviors that would go beyond the fact that the student did not disturb the class. Because the goal of using this vignette was to exclusively illustrate what something is not, it had to be shorter than the description of the disruptive student. Target's gender was randomly varied between subjects, so each participant had to rate either two female targets or two male targets (between-subjects factor). In sum, a 2 (within: targets' behavior [unobtrusive, disruptive]) x 2 (between: targets' gender [male, female]) factorial design was realized. Such a lean design limits the cognitive and motivational burden for the participants as well as the risk of demand effects and was therefore considered the optimal choice for providing a clean first test of the mechanisms of interest. To control for biasing stereotypes elicited merely by particular names, the target students were called "Niklas" (male), "Maximilian" (male), "Jana" (female), or "Maria" (female), which are names that have been rated as equally attractive and intelligent in Germany (Rudolph et al. 2007). To avoid order effects, we systematically varied the presentation order of the two targets as well as the assignment of the names.

After reading the description of the target student, participants were instructed to imagine the target for a moment and to subsequently rate the target on thirteen items with 5-point scales. In detail, the dependent variables were: expected reprimands by the teacher $(1=$ rarely, $5=$ often $)$, teacher's anger $(1=$ rarely, $5=$ often $)$, lack-of-effort attribution ( $1=$ not at all true, $5=$ totally true $)$, lack-of-ability attribution $(1=$ not at all true, $5=$ totally true $)$, ascribed number of friends $(1=a \mathrm{few}$, $5=$ many), popularity $(1=$ not popular, $5=$ very popular $)$, likeability $(1=$ not at all likeable, $5=$ very likeable $)$, wanting to be friends with $(1=$ not at all, $5=$ very much $)$, IQ score ( $1=$ below average, $5=$ above average), masculinity $(1=$ not masculine, $5=$ very masculine $)$, femininity $(1=$ not feminine, $5=$ very feminine $)$, frequency of students like this $(1=$ rarely, $5=$ very often $)$, and gender typicality $(1=$ not similar to a typical boy/girl, $5=$ very similar to a typical boy/girl). For the exact wording of the items, please see Table 1. The items were presented in two groups, the first assessing participants' expectations of teacher reactions and attributions, the second assessing the expected social and gender-related outcomes. After rating the first target student, participants read about the second target student and rated that student.

\subsection{Analytical approach}

To test our hypotheses while taking into account the nested data structure (vignettes nested in participants), we applied multilevel modeling with robust standard errors (MLR) in Mplus 8 (Level 1: 355-356 vignettes, Level 2: 178 participants). Multilevel models are a very flexible approach for analyzing data from (experimental) 


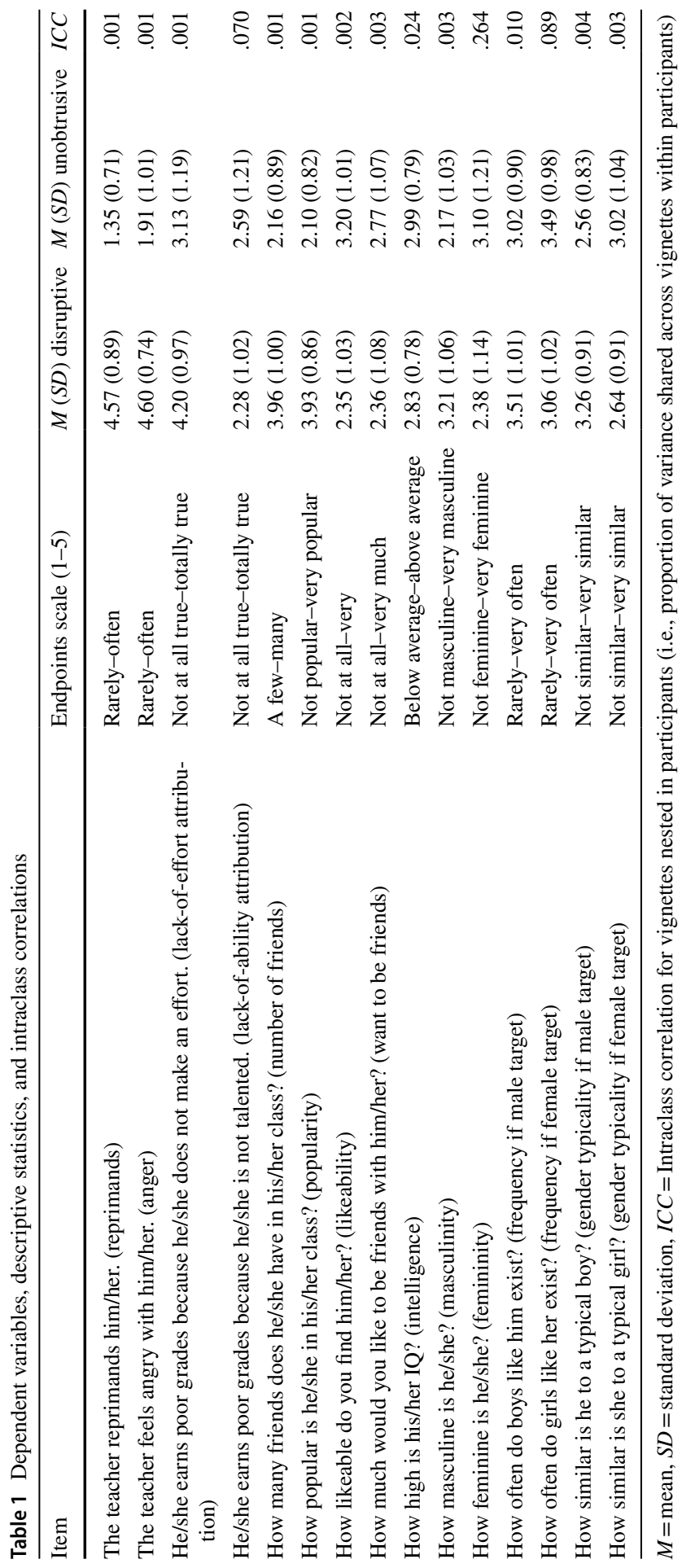


designs with repeated measures (e.g., Hoffman and Rovine 2007; Misangyi et al. 2006) and can be used to conduct lower level mediation analyses (Bolger and Laurenceau 2013). Our treatment variable, i.e., target students' behavior, was coded as $0=$ unobtrusive, $1=$ disruptive. Hypotheses $1,2 \mathrm{a}, 3 \mathrm{a}, 4 \mathrm{a}-\mathrm{c}, 5 \mathrm{c}$, and $5 \mathrm{~d}$ would be supported by significant regression coefficients for targets' behavior in the expected direction. Hypotheses $2 b$ and $3 b$ would be supported by the respective significant indirect effects. Hypotheses $1-4,5 c$ and $5 d$ were tested in models assuming all effects to be fixed. In supplementary analyses, we also specified random slopes models and exploratorily tested whether the effects varied between participants. These results are presented in Appendix A.1, B.1, C.1 and D.1. Hypotheses 5a and $5 \mathrm{~b}$ would be supported by significant interaction effects between target's gender and target's behavior in cross-level interaction models with random slopes. In these models, target students' gender was included as a Level 2 predictor, coded $0=$ female, $1=$ male.

\section{Results}

\subsection{Descriptive results}

The means and standard deviations of the ratings of the target students are presented in Table 1, separately for the disruptive and unobtrusive target students. The intraclass correlations for all dependent variables further revealed that in most cases, only a very small proportion of variance in the ratings was allocated to Level 2 (i.e., between participants). The largest part was on the vignette level (see Table 1).

\subsection{Ascribed teacher reactions and attributions}

Hypotheses 1-3b were tested with lower level mediation models with reprimands and anger as potential mediators of the effect of target students' behavior on lack-ofeffort attributions (Model 1, see Fig. 1) and lack-of-ability attributions (Model 2, see Fig. 2). Because target students' behavior was dichotomous (i.e., $0=$ unobtrusive vs. $1=$ disruptive), we report unstandardized coefficients and effects, which are intuitively meaningful and directly interpretable. In line with our hypotheses, all effects were first assumed to be fixed.

As presented in Figs. 1 and 2, when reading about target students' disruptive behavior, there were significant increases in students' expectations that teachers would reprimand the target students and would be feel anger, supporting Hypothesis 1 which stated that a target student's disruptive behavior would elicit participants' perceptions that teachers would react with reprimands and anger. Further, there was a significant positive total effect of target students' behavior on lack-ofeffort attributions (total effect $=1.06, S E=0.12, p<.001$ ), supporting Hypothesis $2 \mathrm{a}$. The total effect of target students' behavior on lack-of-effort attributions was significantly mediated by teachers' reprimands (specific indirect effect $=0.56, S E=0.28$, $p=.047$ ) but not by teachers' anger (specific indirect effect $=-0.01, S E=0.21$, 


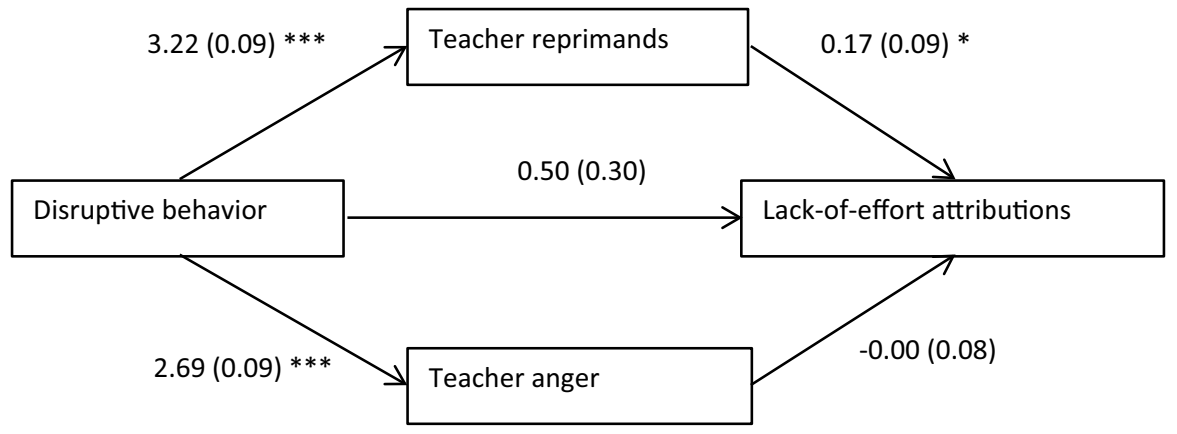

Fig. 1 Lower level mediation model for lack-of-effort attributions with fixed effects. Unstandardized coefficients with standard errors in parentheses. Intercept effort attribution $_{1}=2.92(0.18)^{* * *}$; Level 2 variance $=0.01(0.11)$. Intercept reprimands $_{1}=1.35(0.05)^{* *} ;$ Intercept $_{\text {anger }}=1.91(0.08)^{* * *}$. Level 1 residual variance $_{\text {effort attribution }}=1.15(0.12)^{* * *}$; Level 1 residual variance reprimands $=.65(0.11)^{* * *}$; Level 1 residual variance $_{\text {anger }}=0.78(0.08) * * * * p<.05 . * * * p<.001$

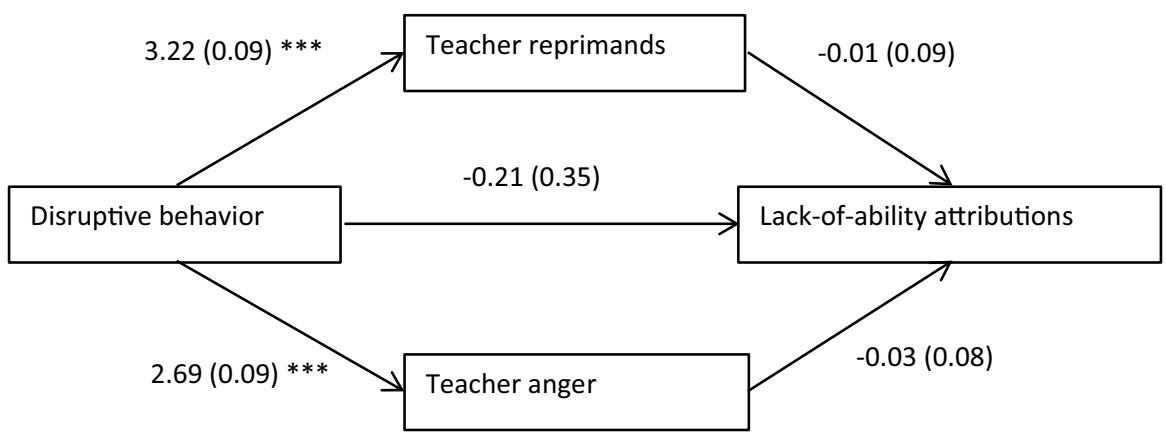

Fig. 2 Lower level mediation model for lack-of-ability attributions with fixed effects. Unstandardized coefficients with standard errors in parentheses. Intercept ${ }_{\text {ability attribution }}=2.65(0.19)^{* * *}$, Level 2 variance $=0.11(0.10)$. Intercept reprimands $=1.35(0.05)^{* * *}$, Intercept $_{\text {anger }}=1.91(0.08)^{* * *}$. Level 1 residual variance $_{\text {ability attribution }}=1.14(0.12)^{* * *}$, Level 1 residual variance reprimands $=0.65(0.11)^{* * *}$, Level 1 residual variance anger $=0.78(0.08) * * * . * * * p .001$

$p=.969$ ), as only teachers' reprimands were directly related to lack-of-effort attributions. The remaining direct effect of disruptive behavior on lack-of-effort attributions was not statistically significant (direct effect $=0.50, S E=0.30, p=.098$ ). Thus, Hypothesis 2a, stating that a target student's disruptive behavior would elicit lack-ofeffort attributions from participants, was fully supported, and Hypothesis $2 \mathrm{~b}$, stating that the effect of a target student's disruptive behavior on participants' lack-of-effort attributions would be mediated by participants' expectations of teachers' reprimands and anger, was supported in part. In addition, we specified a random slope model to explore whether the effects might vary between participants (see Appendix A.1). However, no significant variation in the slopes on Level 2 was found (all $p s>.07$ ), suggesting that the effects held irrespective of the characteristics on Level 2 such as targets' gender or participants' gender. As presented in Fig. 2, expectations of 
teachers' reprimands and anger did not significantly predict lack-of-ability attributions. Although we found a significant total effect of students' behavior on lack-ofability attributions (total effect $=-0.31, S E=0.11, p=.006$ ), specific indirect effects via reprimands (specific indirect effect $=-0.03, S E=0.29, p=.918$ ) and via anger (specific indirect effect $=-0.07, S E=0.22, p=.744$ ) as well as the direct effect of students' behavior (direct effect $=0.21, S E=0.35, p=.547$ ) were not statistically significant. Thus, Hypothesis 3a, stating that a target student's disruptive behavior would elicit lower lack-of-ability attributions from participants for the target student's low achievement, was supported, but Hypothesis $3 \mathrm{~b}$ which stated that this effect would be mediated by participants' expectations of teachers' reprimands and anger, was not. An exploratory random slope model again revealed no significant variation in the slopes on Level 2 (all ps >.08; see Appendix B.1).

\subsection{Social outcomes and intelligence}

To test whether the target's behavior influenced students' social perceptions and the level of intelligence ascribed to the target, we specified target's behavior as a predictor of target's intelligence, number of friends, popularity, likeability, and participants' desire to have the target as a friend. We assumed the effects were fixed and included all covariances between the five outcome variables in the model. The analysis revealed that disruptive behavior increased the ratings of targets' popularity and number of friends as predicted by Hypothesis 4 a (see Table 2). Disruptive behavior further decreased the ratings of targets' likeability and participants' desire to be friends with the target. Thus, Hypothesis $4 \mathrm{~b}$ was also supported by the data. Contrary to our expectations, however, disruptive behavior did not increase the ratings of targets' ascribed intelligence, thus providing no support for Hypothesis 4c which hypothesized that the disruptive target would be perceived as more intelligent. An additional, exploratory random slope model again revealed no significant

Table 2 Random intercept model predicting social outcomes and intelligence

\begin{tabular}{|c|c|c|c|c|c|}
\hline & \multicolumn{5}{|l|}{ Outcomes } \\
\hline & $\begin{array}{l}\text { Number of } \\
\text { friends }\end{array}$ & Popularity & Likeability & $\begin{array}{l}\text { Want to be } \\
\text { friends }\end{array}$ & Intelligence \\
\hline Intercept & $2.16(0.07)^{* * *}$ & $2.07(0.06)^{* * *}$ & $3.18(0.08) * * *$ & $2.75(0.08)^{* * *}$ & $2.99(0.06)^{* * * *}$ \\
\hline $\begin{array}{l}\text { Disrup- } \\
\text { tive } \rightarrow \text { out- } \\
\text { come }\end{array}$ & $1.80(0.11)^{* * *}$ & $1.84(0.12)^{* * *}$ & $-0.82(0.12)^{* * *}$ & $-0.40(0.12)^{* *}$ & $-0.16(0.08)$ \\
\hline $\begin{array}{l}\text { Level } 1 \text { residual } \\
\text { variance }\end{array}$ & $0.89(0.09)^{* * *}$ & $0.75(0.07)^{* * *}$ & $1.03(0.09)^{* * *}$ & $1.11(0.09)^{* * *}$ & $0.58(0.07)^{* * * *}$ \\
\hline Level 2 variance & $0.00(0.05)$ & $0.01(0.05)$ & $0.01(0.05)$ & $0.05(0.07)$ & $0.03(0.05)$ \\
\hline
\end{tabular}

Unstandardized coefficients and standard error in parentheses

$* * p<.01, * * * p<.001$ 
variation in the relationships between disruptive behavior and the outcome variables on Level 2 (all $p s>.16$; see Appendix C.1).

\subsection{Gender-related outcomes}

To test whether disruptive male students are perceived as more frequent and more gender-typical than disruptive female students, we ran a cross-level interaction model with target's behavior (Level 1), target's gender (Level 2), and their interaction as predictors of frequency and gender typicality, which were allowed to covary. As presented in Table 3, all predictors were statistically significant. Supporting Hypotheses 5a and 5b, disruptive male students were perceived as more frequent (H5a) and more gender-typical (H5b) than disruptive female students (see Fig. 3). In terms of predictive power (Aguinis et al. 2013), the significant interaction terms indicate that female students showing disruptive behavior were perceived as 0.44 units less frequent and 0.81 units less gender-typical than male students showing disruptive behavior.

Finally, we tested whether disruptive behavior resulted in higher ascriptions of masculinity and lower ascriptions of femininity (fixed-effects model). Masculinity and femininity were allowed to covary. In support of Hypotheses $5 \mathrm{c}$ and $5 \mathrm{~d}$, showing disruptive behavior resulted in higher ascribed masculinity (H5c) and lower ascribed femininity (see Table 4) (H5d). An additional, exploratory random slope model again revealed no significant variation in the slopes on Level 2 (all $p \mathrm{~s}>.05$; see Appendix D.1).

Table 3 Cross-level interaction model predicting target frequency and gender typicality

\begin{tabular}{lcc}
\hline & \multicolumn{2}{l}{ Outcomes } \\
\cline { 2 - 3 } & Frequency & Gender typicality \\
\hline Intercept & $3.50(0.10)^{* * *}$ & $3.02(0.11)^{* * *}$ \\
Disruptive $\rightarrow$ outcome & $-0.44(0.14)^{* * *}$ & $-0.38(0.16)^{*}$ \\
Male target $\rightarrow$ outcome & $-0.48(0.14)^{* *}$ & $-0.47(0.14)^{* *}$ \\
Disruptive $\times$ male target $\rightarrow$ outcome & $0.92(0.20)^{* * *}$ & $1.08(0.21)^{* * *}$ \\
Level 1 residual variance & $0.76(0.10)^{* * *}$ & $0.83(0.12)^{* * *}$ \\
Level 2 residual variance disruptive $\rightarrow$ outcome & $0.19(0.09)^{*}$ & $0.04(0.10)$ \\
Level 2 residual variance & $0.10(0.09)$ & $0.04(0.10)$ \\
\hline
\end{tabular}

Unstandardized coefficients and standard errors in parentheses. Note that in cross-level interaction models, main effects represent an estimate of the regression when the other variables have a value of zero (Hox 2010)

$* p<.05, * * p<.01, * * * p<.001$ 


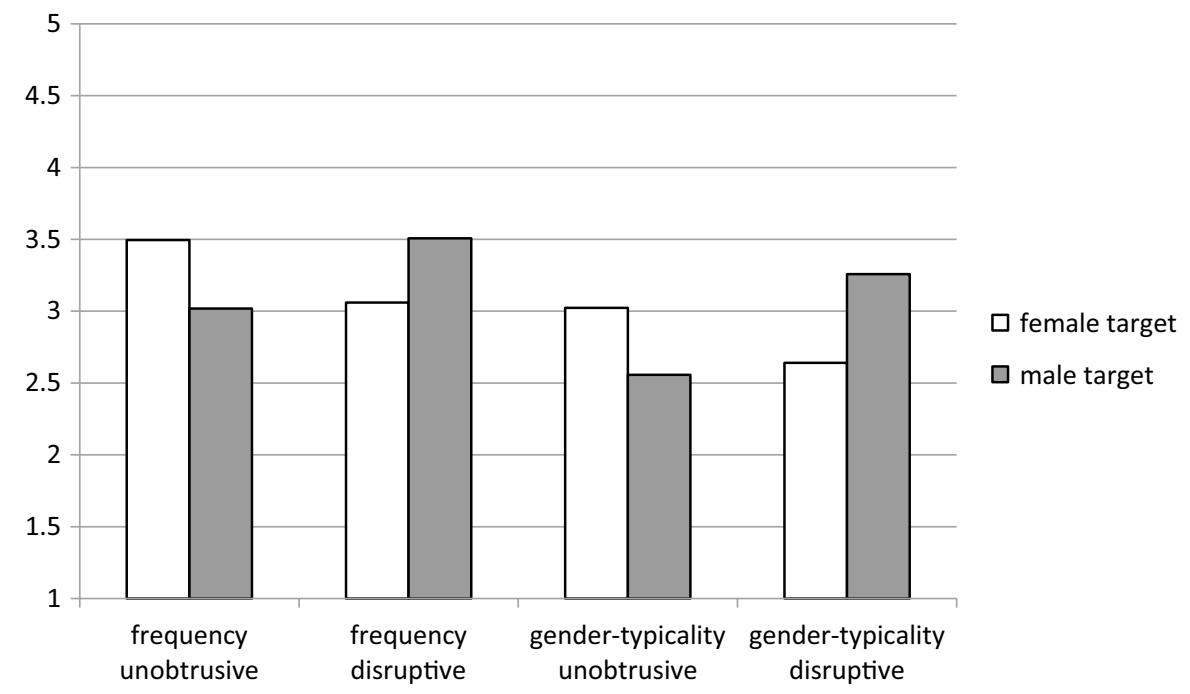

Fig. 3 Interaction effects between targets' gender (male vs. female) and behavior (disruptive vs. unobtrusive) in predicting frequency and gender-typicality. Scales ranged from 1 to 5

Table 4 Random intercept model predicting masculinity and femininity

\begin{tabular}{llr}
\hline & \multicolumn{2}{l}{ Outcomes } \\
\cline { 2 - 3 } & Masculinity & \multicolumn{1}{c}{ Femininity } \\
\hline Intercept & $2.17(0.08)^{* * *}$ & $3.10(0.09)^{* * *}$ \\
Disruptive $\rightarrow$ outcomes & $1.04(0.11)^{* * *}$ & $-0.72(0.10)^{* * *}$ \\
Level 1 residual variance & $1.08(0.11)^{* * *}$ & $0.97(0.10)^{* * *}$ \\
Level 2 variance & $0.00(0.08)$ & $0.36(0.09)^{* * *}$ \\
\hline
\end{tabular}

Unstandardized coefficients and standard error in parentheses $* * * p<.001$

\section{Discussion}

In the current study, we brought together different strands of research in order to test a novel explanation for disruptive behavior in students, that is, the triggering of face-saving attributions for academic failure by evoking teacher reprimands. In an experimental vignette study of German adolescents, we found that target students' disruptive behavior triggered lack-of-effort attributions instead of lackof-ability attributions for low academic achievement. This effect was mediated by students' expectations of teachers' reactions (i.e., high ratings of reprimands). Additional effects of disruptive behavior for low-achieving target students were an increase in ascribed popularity and number of friends but also a decrease in ascribed likeability. Because male students tend to show more disruptive behavior 
than female students (e.g., Finn et al. 2008), we also tested for effects of disruptive behavior on gender-related outcomes. As expected, disruptive behavior increased the ascribed masculinity and decreased the ascribed femininity of the target student, thus suggesting that disruptive behavior is more in line with the male than the female gender role. Accordingly, disruptive male students were perceived as more common and gender-typical than disruptive female students were.

\subsection{Expectations of teachers' reactions and attributions}

Although students expected teachers to react with more reprimands and anger to target students exhibiting disruptive behavior compared with unobtrusive behavior, only reprimands mediated the effect on students' attributions. One plausible explanation for this differential effect is that teachers' reprimands are more visible and audible to students than teachers' emotions. Our study points toward the centrality of teachers' reprimands for lack-of-effort attributions, which is in line with earlier findings that students, from early adolescence on, infer from teachers' reprimands that teachers attribute a students' failure to lack of effort (Butler 1994; Meyer 1992). The current study showed for the first time that others' lackof-effort attributions can be triggered simply by being disruptive in class. This finding complements other research on the role of self-esteem in more severe forms of problem behavior. Problem behavior in itself is discussed as an alternative source of self-esteem for low-achieving students (Baumeister et al. 2003), and longitudinal data have confirmed that students' self-esteem is the mediating link between getting poor grades and showing problem behavior (Zimmermann et al. 2013). However, to date, explanations for how disruptive behavior might increase a low-achieving students' self-esteem have focused primarily on students' redefining their identity and gaining status among peers (Zimmermann et al. 2013). The present study's perspective adds to this research by linking selfworth-protecting attributions of academic failure to disruptive behavior.

Earlier research has focused on the self-worth-protecting effects of self-handicapping for low achievers (for a review, see Urdan and Midgley 2001). By withdrawing effort, procrastinating, and choosing alternative activities over learning, students create (or try to make others believe they have created) a situation in which failure is not diagnostic of their abilities. The present study focused on how disruptive behavior elicits self-serving attributions. In this, our study is related to self-handicapping research but is also distinct from it because the mechanism we proposed and tested was not the link between not working hard and then making self-serving attributions. Rather, the link was between being disruptive and thus being reprimanded, which then serves as a cue to other students that the teacher is making a lack-of-effort attribution.

Although effort and ability attributions work hand in hand in a kind of zerosum game in theory, empirical findings have shown a somewhat less coherent picture. Our predictions of effort attributions were supported because the positive effect of disruptive behavior on effort attributions was mediated by teachers' reprimands. This relationship is fully in line with research that has described 
teachers as reacting to students' failure with punishment and reprimands when students did not put forth effort (e.g., Matteucci 2007; Reyna and Weiner 2001; Weiner and Kukla 1970). However, whereas students' disruptive behavior was also negatively related to lack-of-ability attributions in the current study, this relationship was not mediated by students' expectations of teachers' reactions. Moreover, the total effect of target students' behavior on the ability attribution $(-0.31)$ was roughly only a third of the effect on the effort attribution (1.06).

Whereas lack of effort seems to evoke a specific and perceivable reaction in teachers because it violates the "norm of effort" in the school context (Matteucci and Gosling 2004, p. 147), teachers' reactions following lack-of-ability attributions are much less clear and less visible in teachers' responses to students' answers or behavior in the classroom. Teachers often do not show any active reactions-not even providing direct information in response to a student's incorrect answerwhen they attribute a student's incorrect response to lack of ability, as Butler (1994) showed. Seventy percent of the emotions teachers reported involved compassion and 30\% involved helplessness, whereas no teachers reported feeling anger when making attributions of low ability (compared with two-thirds in the case of lack-ofeffort attributions; Butler 1994). Whereas lack of effort and disrupting the lesson are both actively punished by teachers, both making lack-of-ability attributions and experiencing an unobtrusive student might not elicit any active observable reaction in a teacher that will suggest a lack-of-ability attribution to peers. Taken together, whereas a lower lack-of-ability attribution is theoretically the flipside of a higher lack-of-effort attribution, the teacher's reactions might not be just mirror images in these cases. Even though reprimands indicate a lack of effort, a lack of reprimands does not indicate a lack of ability.

\subsection{Social outcomes and intelligence}

The findings that the disruptive student was conceived of as more popular, but less liked, are fully in line with our hypotheses and earlier findings on students showing low academic effort (De Bruyn and Cillessen 2006; Engels et al. 2017; Heyder and Kessels 2017; Juvonen and Murdock 1995; Lease et al. 2002). However, whereas the contrasting effort and ability attributions for the low grades of disruptive students were found as expected, participants did not rate the disruptive students as more intelligent than the unobtrusive student, albeit this ascription should eventually result when all the inferences outlined in attribution theory are carried out correctly. Several causes might explain this unexpected finding. First, the understanding that if the outcome is equal, lower effort implies higher ability is still developing with children's age (Nicholls 1990). Whereas some older studies suggested that children develop this understanding around the age of 13 (Meyer 1992; Nicholls 1990), it is possible that this pattern will not emerge in all samples at the same time. Nevertheless, because the participants in our study were between the ages of 14 and 15 and came from academic track schools, the interpretation that most students from our sample had not yet acquired this concept would be puzzling. Similar to the results of the current study, however, in a previous study, only teachers but not students from the ninth grade were found to describe the effortless achiever (who excels 
academically without putting forth effort) as more intelligent than the effortful achiever (who works hard to get the same good results; Heyder and Kessels 2017). The authors speculated that the students' view might reflect that they had more of an incremental view than an entity view of intelligence (Dweck 1986). The respective growth mindset is more adaptive and might result from experiencing a pedagogy that promotes the tendency to see abilities not as fixed and limited but as growing with effort and learning. Another explanation for this unexpected finding is that students might perceive disruptive behavior per se as deviant and stupid behavior, which might confound their ratings of a disruptive student's intelligence. It is important to stress that disruptive behavior was in fact successful in evoking more self-serving lack-of-effort attributions and fewer lackof-ability attributions compared with unobtrusive behavior, even if participants refrained from attributing extra intelligence to the troublemaker.

\subsection{Gender-related outcomes}

Regarding this aspect of our research, our results indicate that, irrespective of other benefits, disruptive behavior leads to the ascription of masculinity (see also Jackson 2002), indirectly implying higher benefits for disruptive male students than for disruptive female students. Because being disruptive potentially enhances students' masculinity, boys' problem behavior at school can also serve as a means to confirm group status and manhood. The theory on "precarious manhood," an extension of social identity theory (Tajfel and Turner 1986), states that manhood is a tenuous kind of group status that has to be achieved or earned and has to be constantly confirmed (Vandello et al. 2008). Especially when status is threatened, men tend to enact gender normed-behaviors (e.g., expressing physically aggressive thoughts, Vandello et al. 2008; alcohol use, Fugitt and Ham 2018). As such, academically weak individual male students might use disruptive behavior not only as a means for preventing lack-of-ability attributions but also as prototypical male behavior to maintain status. In addition, at school, boys as a group are also confronted with the gender gap in achievement in favor in girls, threatening their superior group status. Both devaluing girls' accomplishments as resulting from extra effort (Jackson and Dempster 2009) and publicly displaying prototypical male behavior (e.g., being maladjusted and disruptive) might result from boys' collective striving to maintain a superior status nevertheless. Although boys seem to indirectly benefit more from showing disruptive behavior as elaborated above, the current study did not reveal any significant differences between male and female targets or between male and female participants regarding the effectiveness of the triggering of lack-of-effort attributions. The lack of significant variation in the attributional mechanisms and effects at Level 2 supports our assumption that these mechanisms work in similar ways for male and female students. However, in this context, it is important to remember that we varied target students' gender between participants (i.e., on Level 2) rather than within them. Between-subjects factors make it more difficult to detect an effect and are considered to offer a more conservative choice (Charness et al. 2012). Thus, this design might have limited the comparisons participants made 
between male and female target students and, thus, gender-specific effects (see also Heyder and Kessels 2017, for a similar discussion). A full within-subjects design, however, would have required participants to judge up to four vignettes such that each pair would be identical in all aspects except the name (female or male). Multiple treatments in within-subjects designs can make individuals sensitive to the variations between the treatments (Charness et al. 2012) such that participants will ascribe meaning to these varying parameters resulting in a higher risk for demand effects and confoundedness.

\subsection{Implications for the school context}

Although lack-of-effort attributions triggered by disruptive behavior should protect students' self-worth, they might be harmful for students' future academic success. First, not only is disruptive behavior more prevalent among low-achieving students, but it also contributes to their low achievement in the future (Zimmermann et al. 2013). Whereas our results suggest short-term benefits for students with respect to attributions and popularity, in the long run, the mechanism revealed in this study should actually worsen the academic trajectories of low-achieving students. Second, teachers' grading practices are known to be affected not only by students' achievement but also by students' effort and behavior in class (e.g., Kulinna 2007; Randall and Engelhard 2010), so low-achieving students risk to be trapped in a downward spiral of getting ever more bad grades for their behavior which they exhibit mainly as a face-saving strategy after getting low grades.

As in prior studies (e.g., Engels et al. 2017; Heyder and Kessels 2017), we found differential effects on students' popularity and likeability. In the present study, target students showing disruptive behavior were rated as more popular but less liked. Thus, the perceived benefits of showing disruptive behavior might vary not only in accordance with the audience (teachers vs. peers) but also in accordance with students' personal goals (appearing popular vs. being liked), an idea that seems fruitful to explore more deeply in future research. In addition, given that LaFontana and Cillessen (2010) observed that from adolescence on, students' social goals change from being well-liked to being socially dominant, studying different age groups might reveal other differential effects.

The goals that students pursue in school are related to disruptive behavior as well. Goal orientation theory (Ames 1992) distinguishes between mastery goals, which focus on learning and improvement, and performance goals, which focus on social comparison and demonstrating competence or hiding low ability (Elliot 1997). Mastery goals are negatively related to self-handicapping (Midgley and Urdan 2001) and to disruptive behavior on both the individual and classroom levels (Kaplan et al. 2002). Fostering a mastery goal structure in the classroom encompasses instructional practices that focus on meaningful aspects of learning activities and on individual improvement, progress, and mastery, all of which are linked not only to high intrinsic motivation but also to effort attributions (Ames 1992). 
Therefore, emphasizing mastery goals instead of performance goals is a promising way to protect students from withdrawing their effort or disrupting lessons in order to evoke lack-of-effort attributions.

Whereas scientific theory and research has contributed a lot to our understanding of how self-worth issues are related to both attributional processes (e.g., Weiner 1994) and problem behavior (e.g., Zimmermann et al. 2013), teachers still tend to overlook these relationships when explaining disruptive behavior. Unlike students, who see attention-seeking, gaining power, and popularity as causes of misbehavior (Cothran et al. 2009), teachers' view of the causes of problem behavior tend to focus on problematic home environments and poor upbringing (Bibou-Nakou et al. 2000; Cothran et al. 2009; Glock and Kleen 2017) or students' characteristics (Bibou-Nakou et al. 2000). The present study's findings on how low-achieving students elicit self-serving attributions by being disruptive can add to teachers' understanding of poor-performing students' need to gain higher self-esteem by misbehaving. As a consequence, we hope this will inspire teachers to help students employ other more constructive avenues for regaining self-esteem and status. Self-esteem interventions have been shown to be particularly successful when they involve attributional feedback and they target students with pre-existing problems such as low self-esteem (O'Mara et al. 2006). "Positive Action", a comprehensive school-based social-emotional and character-development program, has had a positive impact on self-esteem in the domains of school and peers (Silverthorn et al. 2017). Its curriculum is designed to continually reinforce the concept that positive self-feelings arise from choosing positive actions, and it emphasizes the effortful nature of self-improvement (Silverthorn et al. 2017).

\subsection{Limitations and future research directions}

In this study, we experimentally tested a novel mechanism that we believe contributes to students' disruptive behavior in the classroom. Our findings suggest that, indeed, disruptive behavior can evoke lack-of-effort attributions for low-achieving students. However, our study does not provide information on whether or to what degree students are aware of the mechanism and whether it (consciously or unconsciously) affects the amount of disruptive behavior they actually show. Qualitative interviews with teenagers (Cothran et al. 2009) did not reveal any conscious insights into the relationship between being disruptive and eliciting lack-of-effort attributions. Even if the students themselves were much more aware than the teachers of the beneficial effects of these attributions (e.g., gaining status and power and, for male students, impressing female students; Cothran et al. 2009), the students did not make any reference to self-serving attributions for low achievement. Even when the students did mention seeking the teacher's attention as a reason for being disruptive, they did not mention the elicitation of reprimands for being seen as lazy but able. Instead, they limited their reasoning to simple causes such as "just so he [the teacher] won't forget about them [the disruptive students]" (Cothran et al. 2009, p. 161). It remains a task 
for future research to detect in more detail how students' behavior might be guided not only purposefully by conscious goals but also by psychological mechanisms that are not fully accessible to the students themselves. A first step could be to also assess participants' own disruptive behavior and include this as a quasi-experimental factor. It would then be possible to test whether students who display disruptive behavior themselves are more or less prone than unobtrusive students to make lack-of-effort attributions for disruptive students' academic failures.

Second, our findings should be interpreted against the background of the applied experimental design used in this study. We found mostly strong effects in support of our hypotheses for the within-subjects factor target's behavior but nonsignificant effects for the between-subjects factor of target', gender. These stronger effects for within-subjects designs compared to between-subjects designs has been detected in an earlier study using a similar design (Heyder and Kessels 2017) and derive from the specific strengths and weaknesses of each of these designs as described by Charness et al. (2012). Future research might thus benefit from complementing the present study's findings with results based on other experimental designs, for instance, by including multiple sets of vignettes.

Third, because the vignettes were short and described prototypes rather than individual students and because we aimed to assess participants' first impressions, we used single-item scales. This procedure allowed the dependent variables to match the vignettes regarding breadth of information. Measures with a limited number of items (i.e., one or two) are often used in vignette studies (e.g., Juvonen and Murdock 1995; Muenks et al. 2016; Rentzsch et al. 2011), and there is evidence showing that single items are characterized by high face validity and sufficient reliability (Gogol et al. 2014).

Fourth, the present study focused on attributions for student failure. In future research, it would be fruitful to also test for effects of disruptive behavior for highachieving students, even if high-achieving students show less misbehavior than lowachieving students (e.g., Zimmermann et al. 2013). Even if high-achieving students are generally at less risk of being subjected to low ability attributions compared with low achievers, they might still be motivated to discourage high effort attributions and benefit from the increase in popularity or masculinity revealed in this study.

\subsection{Conclusion}

Disruptive student behavior is a frequent part of daily school life and is a burden for teachers and an obstacle to student learning (e.g., Arbuckle and Little 2004; Moilanen et al. 2010; Sullivan et al. 2014). Prior research has shown that low achievement, low self-esteem, and being male are risk factors for showing disruptive behavior (e.g., Kaplan et al. 2002; Zimmermann et al. 2013). Our study adds to this knowledge by demonstrating that disruptive behavior can serve as a means for low-achieving students to evoke lack-of-effort attributions, higher popularity 
ratings, and a masculine image. For the first effect, students' expectations of teachers' public reactions to the misbehaving student (i.e., being reprimanded by the teacher in front of peers) seems to be a crucial mediating variable. Therefore, in line with teachers being the "most important element of the education system" (Baumert and Kunter 2013, p. 25), teachers also seem crucial for applying these results in daily school practice. Disseminating the effects and mechanisms to other teachers, supporting them in providing students with mastery-goal-oriented learning environments, or implementing programs aimed at fostering students' selfesteem are potential steps toward reducing students' need for public lack-of-effort attributions. Subsequently, if they no longer desire such lack-of-effort attributions, then low-achieving students might show less disruptive behavior, thereby ending the downward spiral that exists between disruptive behavior and poor educational trajectories.

Acknowledgements Open Access funding provided by Projekt DEAL. The German Research Foundation (DFG), the Senate Administration for Education, Youth, and Science in charge of approving empirical research in schools in Berlin, Germany, and the headmasters of the participating schools reviewed and approved the research protocol and questionnaires.

Funding The current research was supported by a Grant from the Deutsche Forschungsgemeinschaft (DFG) allocated to the first author (KE 1412/2-2). Open Access funding provided by Projekt DEAL.

\section{Compliance with ethical standards}

Conflict of interest The authors declare that they have no conflict of interest.

Ethical approval The German Research Foundation (DFG), the Senate Administration for Education, Youth, and Science in charge of approving empirical research in schools in Berlin, Germany, and the headmasters of the participating schools reviewed and approved the research protocol and questionnaires. A further approval of the protocol by the university ethics committee is not required for projects of this type because research on school students is under direct supervision of the Senate Administration for Education, Youth, and Science.

Informed consent Participation was voluntary and informed consent was secured from all participants. All participants were at least 14 years old, meaning that parental permissions did not have to be obtained according to the regulations of the Senate Administration. No identifying information was obtained from participants and we had no reason to assume that our study would do any harm. Participants were fully debriefed afterwards.

Open Access This article is licensed under a Creative Commons Attribution 4.0 International License, which permits use, sharing, adaptation, distribution and reproduction in any medium or format, as long as you give appropriate credit to the original author(s) and the source, provide a link to the Creative Commons licence, and indicate if changes were made. The images or other third party material in this article are included in the article's Creative Commons licence, unless indicated otherwise in a credit line to the material. If material is not included in the article's Creative Commons licence and your intended use is not permitted by statutory regulation or exceeds the permitted use, you will need to obtain permission directly from the copyright holder. To view a copy of this licence, visit http://creativecommons.org/licen ses/by/4.0/. 


\section{Appendix}

Table A.1 Random slope mediation model for lack-of-effort attributions

\begin{tabular}{|c|c|c|c|}
\hline & Coefficient & Standard error & $p$ value \\
\hline \multicolumn{4}{|l|}{ Level 1 intercepts } \\
\hline Anger & 1.91 & 0.08 & $<.001$ \\
\hline Reprimands & 1.35 & 0.05 & $<.001$ \\
\hline \multicolumn{4}{|l|}{ Level 1 residual variances } \\
\hline Anger & 0.75 & 0.07 & $<.001$ \\
\hline Reprimands & 0.48 & 0.12 & $<.001$ \\
\hline Lack-of-effort attributions & 0.97 & 0.19 & $<.001$ \\
\hline \multicolumn{4}{|l|}{ Level 2 means } \\
\hline Lack-of-effort attributions & 2.97 & 0.45 & $<.001$ \\
\hline Disruptive $\rightarrow$ lack-of-effort attributions & 0.74 & 0.84 & .378 \\
\hline Disruptive $\rightarrow$ anger & 2.68 & 0.09 & $<.001$ \\
\hline Disruptive $\rightarrow$ reprimands & 3.22 & 0.09 & $<.001$ \\
\hline Anger $\rightarrow$ lack-of-effort attributions & 0.03 & 0.17 & .878 \\
\hline Reprimands $\rightarrow$ lack-of-effort attributions & 0.08 & 0.16 & .610 \\
\hline \multicolumn{4}{|l|}{ Level 2 variances } \\
\hline Lack-of-effort attributions & 0.01 & 0.20 & .971 \\
\hline Disruptive $\rightarrow$ lack-of-effort attributions & 1.74 & 1.79 & .331 \\
\hline Disruptive $\rightarrow$ anger & 0.05 & 0.32 & .868 \\
\hline Disruptive $\rightarrow$ reprimands & 0.33 & 0.19 & .078 \\
\hline Anger $\rightarrow$ lack-of-effort attributions & 0.05 & 0.04 & .200 \\
\hline Reprimands $\rightarrow$ lack-of-effort attributions & 0.04 & 0.06 & .475 \\
\hline
\end{tabular}

Unstandardized coefficients. All slopes were allowed to covary between subjects (figures not presented) 
Table B.1 Random slope mediation model for lack-of-ability attributions

\begin{tabular}{|c|c|c|c|}
\hline & Coefficient & Standard error & $p$ value \\
\hline \multicolumn{4}{|l|}{ Level 1 intercepts } \\
\hline Anger & 1.91 & 0.08 & $<.001$ \\
\hline Reprimands & 1.35 & 0.05 & $<.001$ \\
\hline \multicolumn{4}{|l|}{ Level 1 residual variances } \\
\hline Anger & 0.76 & 0.07 & $<.001$ \\
\hline Reprimands & 0.48 & 0.11 & $<.001$ \\
\hline Lack-of-ability attributions & 0.92 & 0.26 & $<.001$ \\
\hline \multicolumn{4}{|l|}{ Level 2 means } \\
\hline Lack-of-ability attributions & 2.72 & 0.46 & $<.001$ \\
\hline Disruptive $\rightarrow$ lack-of-ability attributions & -0.06 & 0.79 & .939 \\
\hline Disruptive $\rightarrow$ anger & 2.68 & 0.09 & $<.001$ \\
\hline Disruptive $\rightarrow$ reprimands & 3.22 & 0.09 & $<.001$ \\
\hline Anger $\rightarrow$ lack-of-ability attributions & -0.04 & 0.37 & .926 \\
\hline Reprimands $\rightarrow$ lack-of-ability attributions & -0.05 & 0.20 & .797 \\
\hline \multicolumn{4}{|l|}{ Level 2 variances } \\
\hline Lack-of-ability attributions & 0.17 & 0.18 & .329 \\
\hline Disruptive $\rightarrow$ lack-of-ability attributions & 1.47 & 2.02 & .465 \\
\hline Disruptive $\rightarrow$ anger & 0.05 & 0.39 & .894 \\
\hline Disruptive $\rightarrow$ reprimands & 0.33 & 0.19 & .087 \\
\hline Anger $\rightarrow$ lack-of-ability attributions & 0.05 & 0.07 & .459 \\
\hline Reprimands $\rightarrow$ lack-of-ability attributions & 0.02 & 0.13 & .864 \\
\hline
\end{tabular}

Unstandardized coefficients. All slopes were allowed to covary between subjects (figures not presented)

Table C.1 Random slope regression model predicting social outcomes and intelligence

\begin{tabular}{|c|c|c|c|c|c|}
\hline & \multicolumn{5}{|l|}{ Outcomes } \\
\hline & $\begin{array}{l}\text { Number of } \\
\text { friends }\end{array}$ & Popularity & Likeability & $\begin{array}{l}\text { Want to be } \\
\text { friends }\end{array}$ & Intelligence \\
\hline $\begin{array}{l}\text { Level } 1 \text { residual } \\
\text { variance }\end{array}$ & $0.80(0.10)^{* * *}$ & $0.69(0.07)^{* * *}$ & $1.03(0.10)^{* * *}$ & $1.12(0.10) * * *$ & $0.58(0.08)^{* * * *}$ \\
\hline \multicolumn{6}{|l|}{ Level 2 means } \\
\hline Outcome & $2.16(0.07)^{* * *}$ & $2.08(0.06)^{* * *}$ & $3.19(0.08)^{* * *}$ & $2.77(0.08)^{* * *}$ & $2.99(0.06)^{* * *}$ \\
\hline $\begin{array}{l}\text { Disrup- } \\
\quad \text { tive } \rightarrow \text { out- } \\
\text { come }\end{array}$ & $1.80(0.11)^{* * *}$ & $1.84(0.10)^{* * *}$ & $-0.83(0.12)^{* * *}$ & $-0.41(0.12)^{* *}$ & $-0.16(0.08)$ \\
\hline \multicolumn{6}{|l|}{ Level 2 variances } \\
\hline Outcome & $<0.01(0.05)$ & $<0.01(0.05)$ & $0.01(0.05)$ & $0.04(0.06)$ & $0.02(0.05)$ \\
\hline $\begin{array}{l}\text { Disrup- } \\
\text { tive } \rightarrow \text { out- } \\
\text { come }\end{array}$ & $0.16(0.11)$ & $0.11(0.09)$ & $<0.01(0.09)$ & $<0.01(0.10)$ & $0.02(0.09)$ \\
\hline
\end{tabular}

Unstandardized coefficients and standard error in parentheses

$* * p<.01, * * * p<.001$ 
Table D.1 Random slope regression model predicting masculinity and femininity

\begin{tabular}{lcc}
\hline & \multicolumn{2}{l}{ Outcomes } \\
\cline { 2 - 3 } & Masculinity & Femininity \\
\hline Level 1 residual variance & $0.98(0.11)^{* * * *}$ & $0.93(0.11)^{* * *}$ \\
Level 2 means & & \\
Outcome & $2.17(0.08)^{* * *}$ & $3.10(0.09)^{* * *}$ \\
Disruptive $\rightarrow$ outcome & $1.04(0.11)^{* * *}$ & $-0.72(0.10)^{* * *}$ \\
Level 2 variances & & \\
Outcome & $<0.01(0.08)$ & $0.35(0.09)^{* * *}$ \\
Disruptive $\rightarrow$ outcome & $0.23(0.12)$ & $0.10(0.11)$ \\
\hline
\end{tabular}

Unstandardized coefficients and standard error in parentheses $* * * p<.001$

\section{References}

Aguinis, H., Gottfredson, R. K., \& Culpepper, S. A. (2013). Best-practice recommendations for estimating cross-level interaction effects using multilevel modeling. Journal of Management, 39(6), 14901528. https://doi.org/10.1177/0149206313478188.

Ames, C. (1992). Classrooms: Goals, structures, and student motivation. Journal of Educational Psychology, 84, 261-271.

Arbuckle, C., \& Little, E. (2004). Teachers' perceptions and management of disruptive classroom behaviour during the middle years (years five to nine). Australian Journal of Educational \& Developmental Psychology, 4, 59-70.

Baumeister, R. F., Campbell, J. D., Krueger, J. I., \& Vohs, K. D. (2003). Does high self-esteem cause better performance, interpersonal success, happiness, or healthier lifestyles? Psychological Science in the Public Interest, 4, 1-44. https://doi.org/10.1111/1529-1006.01431.

Baumert, J., \& Kunter, M. (2013). The COACTIV model of teachers' professional competence. In M. Kunter, J. Baumert, W. Blum, U. Klusmann, S. Krauss, \& M. Neubrand (Eds.), Cognitive activation in the mathematics classroom and professional competence of teachers. Results from the COACTIV project (pp. 25-48). New York: Springer.

Beaman, R., Wheldall, K., \& Kemp, C. (2006). Differential teacher attention to boys and girls in the classroom. Educational Review, 58, 339-366. https://doi.org/10.1080/00131910600748406.

Beaman, R., Wheldall, K., \& Kemp, C. (2007). Recent research on troublesome classroom behaviour: A review. Australasian Journal of Special Education, 31, 45-60. https://doi.org/10.1080/1030011070 1189014.

Bibou-Nakou, I., Kiosseoglou, G., \& Stogiannidou, A. (2000). Elementary teachers' perceptions regarding school behavior problems: Implications for school psychological services. Psychology in the Schools, 37, 123-134.

Bolger, N., \& Laurenceau, J.-P. (2013). Intensive longitudinal methods: An introduction to diary and experience sampling research. New York: Guilford Press.

Breslau, N., Breslau, J., Miller, E., \& Raykov, T. (2011). Behavior problems at ages 6 and 11 and high school academic achievement: Longitudinal latent variable modeling. Psychiatry Research, 185, 433-437. https://doi.org/10.1016/j.psychres.2010.07.027.

Buchmann, C., DiPrete, T. A., \& McDaniel, A. (2008). Gender inequalities in education. Annual Review of Sociology, 34, 319-337. https://doi.org/10.1146/annurev.soc.34.040507.134719.

Butler, R. (1994). Teacher communications and student interpretations: Effects of teacher responses to failing students on attributional inferences in two age groups. British Journal of Educational Psychology, 64, 277-294. https://doi.org/10.1111/j.2044-8279.1994.tb01102.x.

Charness, G., Genîzî, Û., \& Kuhn, M. A. (2012). Experimental methods: Between-subject and withinsubject design. Journal of Economic Behavior \& Organization, 81, 1-8. https://doi.org/10.1016/j. jebo.2011.08.009. 
Cillessen, A. H. N., \& Marks, P. E. L. (2011). Conceptualizing and measuring popularity. In A. H. N. Cillessen, D. Schwartz, \& L. Mayeux (Eds.), Popularity in the peer system (pp. 25-56). New York, NY: Guilford Press.

Cillessen, A. H. N., \& Mayeux, L. (2004). From censure to reinforcement: Developmental changes in the association between aggression and social status. Child Development, 75, 147-163. https://doi.org/1 0.1111/j.1467-8624.2004.00660.x.

Collie, R. J., Shapka, J. D., \& Perry, N. E. (2012). School climate and social-emotional learning: Predicting teacher stress, job satisfaction, and teaching efficacy. Journal of Educational Psychology, 104, 1189-1204.

Cook, C. R., Dart, E., Collins, T., Restori, A., Daikos, C., \& Delport, J. (2012). Preliminary study of the confined, collateral, and combined effects of reading and behavioral interventions: Evidence for a transactional relationship. Behavioral Disorders, 38, 38-56. https://doi.org/10.1177/0198742912 03800104.

Cothran, D. J., Kulinna, P. H., \& Garrahy, D. A. (2009). Attributions for and consequences of student misbehavior. Physical Education and Sport Pedagogy, 14, 155-167. https://doi. org/10.1080/17408980701712148.

De Bruyn, E. H., \& Cillessen, A. H. (2006). Popularity in early adolescence: Prosocial and antisocial subtypes. Journal of Adolescent Research, 21(6), 607-627.

Demanet, J., \& Van Houtte, M. (2012). School belonging and school misconduct: The differing role of teacher and peer attachment. Journal of Youth and Adolescence, 41, 499-514. https://doi. org/10.1007/s10964-011-9674-2.

DiPrete, T. A., \& Jennings, J. L. (2012). Social and behavioral skills and the gender gap. Social Science Research, 41, 1-15. https://doi.org/10.1016/j.ssresearch.2011.09.001.

Dweck, C. S. (1986). Motivational processes affecting learning. American Psychologist, 41, 1040-1048.

Elliot, A. J. (1997). Integrating the "classic" and "contemporary" approaches to achievement motivation: A hierarchical model of approach and avoidance achievement motivation. In M. L. Maehr \& P. R. Pintrich (Eds.), Advances in motivation and achievement (Vol. 10, pp. 143-179). Greenwich, CT: JAI Press.

Engels, M. C., Colpin, H., van Leeuwen, K., Bijttebier, P., van Den Noortgate, W., Claes, S., et al. (2017). School engagement trajectories in adolescence: The role of peer likeability and popularity. Journal of School Psychology, 64, 61-75. https://doi.org/10.1016/j.jsp.2017.04.006.

Finn, J. D., Fish, R. M., \& Scott, L. A. (2008). Educational sequelae of high school misbehavior. The Journal of Educational Research, 101, 259-274. https://doi.org/10.3200/JOER.101.5.259-274.

Francis, B. (2000). The gendered subject: Students' subject preferences and discussions of gender and subject ability. Oxford Review of Education, 26, 35-48. https://doi.org/10.1080/0305498001 03845 .

Fugitt, J. L., \& Ham, L. S. (2018). Beer for "brohood": A laboratory simulation of masculinity confirmation through alcohol use behaviors in men. Psychology of Addictive Behaviors, 32, 358-364. https:// doi.org/10.1037/adb0000351.

Georgiou, S. N., Christou, C., Stavrinides, P., \& Panaoura, G. (2002). Teacher attributions of student failure and teacher behavior toward the failing student. Psychology in the Schools, 39, 583-595. https://doi.org/10.1002/pits.10049.

Glock, S. (2016). Stop talking out of turn: The influence of students' gender and ethnicity on preservice teachers' intervention strategies for student misbehavior. Teaching and Teacher Education, 56, 106114. https://doi.org/10.1016/j.tate.2016.02.012.

Glock, S., \& Kleen, H. (2017). Gender and student misbehavior: Evidence from implicit and explicit measures. Teaching and Teacher Education, 67, 93-103. https://doi.org/10.1016/j.tate.2017.05.015.

Gogol, K., Brunner, M., Goetz, T., Martin, R., Ugen, S., Keller, U., et al. (2014). "My questionnaire is too long!" The assessments of motivational-affective constructs with three-item and single-item measures. Contemporary Educational Psychology, 39(3), 188-205. https://doi.org/10.1016/j.cedps ych.2014.04.002.

Graham, S. (1984). Teacher feelings and student thoughts: An attributional approach to affect in the classroom. The Elementary School Journal, 85, 91-104. https://doi.org/10.1086/461394.

Heyder, A., \& Kessels, U. (2013). Is school feminine? Implicit gender stereotyping of school as a predictor of academic achievement. Sex Roles, 69, 605-617. https://doi.org/10.1007/s11199-013-0309-9. 
Heyder, A., \& Kessels, U. (2015). Do teachers equate male and masculine with lower academic engagement? How students' gender enactment triggers gender stereotypes at school. Social Psychology of Education, 18, 467-485. https://doi.org/10.1007/s11218-015-9303-0.

Heyder, A., \& Kessels, U. (2017). Boys don't work? On the psychological benefits of showing low effort in high school. Sex Roles, 77, 72-85. https://doi.org/10.1007/s11199-016-0683-1.

Hinshaw, S. P. (1992). Externalizing behavior problems and academic underachievement in childhood and adolescence: Causal relationships and underlying mechanisms. Psychological Bulletin, 111(1), $127-155$.

Hoffman, L., \& Rovine, M. J. (2007). Multilevel models for the experimental psychologist: Foundations and illustrative examples. Behavior Research Methods, 39, 101-117. https://doi.org/10.3758/BF031 92848.

Hox, J. J. (2010). Multilevel analysis: Techniques and applications (2nd ed.). New York: Routledge.

Jackson, C. (2002). 'Laddishness' as a self-worth protection strategy. Gender and Education, 14, 37-50. https://doi.org/10.1080/09540250120098870.

Jackson, C., \& Dempster, S. (2009). 'I sat back on my computer ... with a bottle of whisky next to me': Constructing 'cool' masculinity through 'effortless' achievement in secondary and higher education. Journal of Gender Studies, 18, 341-356. https://doi.org/10.1080/09589230903260019.

Jones, S., \& Myhill, D. (2004). 'Troublesome boys' and 'compliant girls': Gender identity and perceptions of achievement and underachievement. British Journal of Sociology of Education, 25, 547561. https://doi.org/10.1080/0142569042000252044.

Juvonen, J. (2000). The social functions of attributional face-saving tactics among early adolescents. Educational Psychology Review, 12, 15-32. https://doi.org/10.1023/A:1009080816191.

Juvonen, J., \& Murdock, T. B. (1995). Grade-level differences in the social value of effort: Implications for self-presentation tactics of early adolescents. Child Development, 66, 1694-1705. https://doi. org/10.1111/j.1467-8624.1995.tb00959.x.

Kaplan, A., Gheen, M., \& Midgley, C. (2002). Classroom goal structure and student disruptive behaviour. British Journal of Educational Psychology, 72, 191-211. https://doi.org/10.1348/000709902158847

Kessels, U., Heyder, A., Latsch, M., \& Hannover, B. (2014). How gender differences in academic engagement relate to students' gender identity. Educational Research, 56, 219-228. https://doi. org/10.1080/00131881.2014.898916.

Kessels, U., Warner, L. M., Holle, J., \& Hannover, B. (2008). Threat to identity through positive feedback about academic performance. Zeitschrift für Entwicklungspsychologie und pädagogische Psychologie, 40, 22-31. https://doi.org/10.1026/0049-8637.40.1.22.

Krahé, B., Berger, A., \& Möller, I. (2007). Development and validation of an inventory for measuring gender role self-concept in adolescence. Zeitschrift für Sozialpsychologie, 38, 195-208. https://doi. org/10.1024/0044-3514.38.3.195.

Kulinna, P. H. (2007). Teachers' attributions and strategies for student misbehavior. The Journal of Classroom Interaction, 42, 21-30.

LaFontana, K. M., \& Cillessen, A. H. N. (2010). Developmental changes in the priority of perceived status in childhood and adolescence. Social Development, 19, 130-147. https://doi.org/10.111 1/j.1467-9507.2008.00522.x.

Lease, A. M., Musgrove, K. T., \& Axelrod, J. L. (2002). Dimensions of social status in preadolescent peer groups: Likability, perceived popularity, and social dominance. Social Development, 11, 508533. https://doi.org/10.1111/1467-9507.00213.

Lewis, R., Romi, S., Qui, X., \& Katz, Y. J. (2005). Teachers' classroom discipline and student misbehavior in Australia, China and Israel. Teaching and Teacher Education, 21, 729-741. https://doi. org/10.1016/j.tate.2005.05.008.

Lynch, R. J., Kistner, J. A., \& Allan, N. P. (2014). Distinguishing among disruptive behaviors to help predict high school graduation: Does gender matter? Journal of School Psychology, 52(4), 407-418. https://doi.org/10.1016/j.jsp.2014.05.001.

Määttä, S., Stattin, H., \& Nurmi, J.-E. (2006). Achievement strategies in peer groups and adolescents' school adjustment and norm-breaking behavior. Scandinavian Journal of Psychology, 47, 273-280. https://doi.org/10.1111/j.1467-9450.2006.00517.x.

Matteucci, M. C. (2007). Teachers facing school failure: The social valorization of effort in the school context. Social Psychology of Education, 10, 29-53. https://doi.org/10.1007/s11218-006-9011-x. 
Matteucci, M. C., \& Gosling, P. (2004). Italian and French teachers faced with pupil's academic failure: The "norm of effort". European Journal of Psychology of Education, 19, 147-166. https://doi. org/10.1007/BF03173229.

McClowry, S. G., Rodriguez, E. T., Tamis-LeMonda, C. S., Spellmann, M. E., Carlson, A., \& Snow, D. L. (2013). Teacher/student interactions and classroom behavior: The role of student temperament and gender. Journal of Research in Childhood Education, 27, 283-301. https://doi.org/10.1080/02568 543.2013.796330.

McCrea, S. M., \& Hirt, E. R. (2001). The role of ability judgments in self-handicapping. Personality and Social Psychology Bulletin, 27, 1378-1389. https://doi.org/10.1177/01461672012710013.

Meyer, W. U. (1992). Paradoxical effects of praise and criticism on perceived ability. European Review of Social Psychology, 3, 259-283. https://doi.org/10.1080/14792779243000087.

Midgley, C., \& Urdan, T. (2001). Academic self-handicapping and achievement goals: A further examination. Contemporary Educational Psychology, 26, 61-75. https://doi.org/10.1006/ceps.2000.1041.

Misangyi, V. F., LePine, J. A., Algina, J., \& Goeddeke, F. (2006). The adequacy of repeated-measures regression for multilevel research. Organizational Research Methods, 9, 5-28. https://doi. org/10.1177/1094428105283190.

Moilanen, K. L., Shaw, D. S., \& Maxwell, K. L. (2010). Developmental cascades: Externalizing, internalizing, and academic competence from middle childhood to early adolescence. Development and Psychopathology, 22, 635-653. https://doi.org/10.1017/S0954579410000337.

Morgan, P. L., \& Sideridis, G. D. (2013). Academic and behavioral difficulties at school: Introduction to the special issue. Behavioral Disorders, 38, 193-200. https://doi.org/10.1177/019874291303800 402 .

Muenks, K., Miele, D. B., \& Wigfield, A. (2016). How students' perceptions of the source of effort influence their ability evaluations of other students. Journal of Educational Psychology, 108(3), 438454. https://doi.org/10.1037/edu0000068.

Mullola, S., Ravaja, N., Lipsanen, J., Alatupa, S., Hintsanen, M., Jokela, M., et al. (2012). Gender differences in teachers' perceptions of students' temperament, educational competence, and teachability. British Journal of Educational Psychology, 82, 185-206. https://doi.org/10.111 1/j.2044-8279.2010.02017.x.

Nicholls, J. G. (1990). What is ability and why are we mindful of it? A developmental perspective. In R. J. Sternberg \& J. Kolligian (Eds.), Competence considered (pp. 11-40). New Haven: Yale University Press.

O’Mara, A. J., Marsh, H. W., Craven, R. G., \& Debus, R. L. (2006). Do self-concept interventions make a difference? A synergistic blend of construct validation and meta-analysis. Educational Psychologist, 41, 181-206. https://doi.org/10.1207/s15326985ep4103_4.

Randall, J., \& Engelhard, G. (2010). Examining the grading practices of teachers. Teaching and Teacher Education, 26, 1372-1380. https://doi.org/10.1016/j.tate.2010.03.008.

Raviv, A., Bar-Tal, D., Raviv, A., \& Levit, R. (1983). Students' reactions to attributions of ability and effort. British Journal of Educational Psychology, 53, 1-13. https://doi. org/10.1111/j.2044-8279.1983.tb02530.x.

Rentzsch, K., Schütz, A., \& Schröder-Abé, M. (2011). Being labeled nerd: Factors that influence the social acceptance of high-achieving students. The Journal of Experimental Education, 79(2), 143168. https://doi.org/10.1080/00220970903292900.

Reyna, C., \& Weiner, B. (2001). Justice and utility in the classroom: An attributional analysis of the goals of teachers' punishment and intervention strategies. Journal of Educational Psychology, 93, 309-319. https://doi.org/10.1037/0022-0663.93.2.309.

Rhodewalt, F., \& Fairfield, M. (1991). Claimed self-handicaps and the self-handicapper: The relation of reduction in intended effort to performance. Journal of Research in Personality, 25, 402-417. https ://doi.org/10.1016/0092-6566(91)90030-T.

Rudolph, U., Böhm, R., \& Lummer, M. (2007). A name says more than a thousand words: The social perception of first names. Zeitschrift für Sozialpsychologie, 38, 17-31. https://doi. org/10.1024/0044-3514.38.1.17.

Silverthorn, N., DuBois, D. L., Lewis, K. M., Reed, A., Bavarian, N., Day, J., et al. (2017). Effects of a school-based social-emotional and character development program on self-esteem levels and processes: A cluster-randomized controlled trial. SAGE Open, 7(3), 2158244017713238.

Skaalvik, E. M., \& Skaalvik, S. (2017). Dimensions of teacher burnout: Relations with potential stressors at school. Social Psychology of Education, 20(4), 775-790. https://doi.org/10.1007/s1121 8-017-9391-0. 
Spinath, B., Eckert, C., \& Steinmayr, R. (2014). Gender differences in school success: What are the roles of students' intelligence, personality and motivation? Educational Research, 56, 230-243. https:// doi.org/10.1080/00131881.2014.898917.

Sullivan, A. M., Johnson, B., Owens, L., \& Conway, R. (2014). Punish them or engage them? Teachers' views of unproductive student behaviours in the classroom. Australian Journal of Teacher Education, 39, 43-56. https://doi.org/10.14221/ajte.2014v39n6.6.

Tajfel, H., \& Turner, J. C. (1986). The social identity theory of inter-group behavior. In S. Worchel \& L. W. Austin (Eds.), Psychology of intergroup relations (pp. 7-24). Chicago, IL: Nelson-Hall.

Trautwein, U., Köller, O., \& Baumert, J. (2004). One man's meat is another man's poison: Psychosocial consequences of adolescents' problem behavior in school. Zeitschrift für pädagogische Psychologie, 18, 15-29. https://doi.org/10.1024/1010-0652.18.1.15.

Tsouloupas, C. N., Carson, R. L., Matthews, R., Grawitch, M. J., \& Barber, L. K. (2010). Exploring the association between teachers' perceived student misbehaviour and emotional exhaustion: The importance of teacher efficacy beliefs and emotion regulation. Educational Psychology, 30, 173189. https://doi.org/10.1080/01443410903494460.

Urdan, T., \& Midgley, C. (2001). Academic self-handicapping: What we know, what more there is to learn. Educational Psychology Review, 13, 115-138. https://doi.org/10.1023/A:1009061303214.

van der Linden, D., Scholte, R. H., Cillessen, A. H. N., Nijenhuis, J., \& Segers, E. (2010). Classroom ratings of likeability and popularity are related to the Big Five and the general factor of personality. Journal of Research in Personality, 44, 669-672. https://doi.org/10.1016/j.jrp.2010.08.007.

Vandello, J. A., Bosson, J. K., Cohen, D., Burnaford, R. M., \& Weaver, J. R. (2008). Precarious manhood. Journal of Personality and Social Psychology, 95(6), 1325-1339. https://doi.org/10.1037/a0012453.

Voyer, D., \& Voyer, S. D. (2014). Gender differences in scholastic achievement: A meta-analysis. Psychological Bulletin, 140, 1174-1204. https://doi.org/10.1037/a0036620.

Weiner, B. (1994). Integrating social and personal theories of achievement striving. Review of Educational Research, 64, 557-573.

Weiner, B. (1995). Judgments of responsibility: A foundation for a theory of social conduct. New York: Guilford.

Weiner, B. (2000). Intrapersonal and interpersonal theories of motivation from an attributional perspective. Educational Psychology Review, 12, 1-14. https://doi.org/10.1023/A:1009017532121.

Weiner, B., Graham, S., Stern, P., \& Lawson, M. E. (1982). Using affective cues to infer causal thoughts. Developmental Psychology, 18, 278-286. https://doi.org/10.1037/0012-1649.18.2.278.

Weiner, B., \& Kukla, A. (1970). An attributional analysis of achievement motivation. Journal of Personality and Social Psychology, 15, 1-20. https://doi.org/10.1037/h0029211.

Zimmermann, F., Schütte, K., Taskinen, P., \& Köller, O. (2013). Reciprocal effects between adolescent externalizing problems and measures of achievement. Journal of Educational Psychology, 105, 747-761. https://doi.org/10.1037/a0032793.

Publisher's Note Springer Nature remains neutral with regard to jurisdictional claims in published maps and institutional affiliations.

Ursula Kessels earned her doctoral degree in psychology in 2001 and held the chair for Educational Psychology at the University of Cologne from 2009 to 2013. She now holds the chair for Educational Research/Heterogeneity at the Freie Universität Berlin. Her research interests include the role of stereotypes for students' academic outcomes, focusing the interplay between students' gender and ethnic identity and their motivation, evaluation, and subjective well-being.

Anke Heyder earned her doctoral degree in psychology at the Freie Universität Berlin. Since 2016, she works as a post-doctoral researcher at the TU Dortmund University. Her research focuses on the role of teachers' and students' beliefs and knowledge in explaining individual and gender-related differences in academic achievement and motivation. 